\title{
CIENTISTAS ESPLÊNDIDOS, JORNALISTAS DESNECESSÁRIOS? AS RELAÇÕES DE PODER NA PRODUÇÃO JORNALÍSTICA SOBRE C\&T NA REGIÃO DE FRONTEIRA DO RS
}

\author{
Splendid scientists, unnecessary journalists? \\ The relations of power in journalistic production on $S \& T$ \\ in the RS border region \\ ¿Científicos espléndidos, periodistas innecesarios? \\ Las relaciones de poder en la producción periodística sobre $C \& T$ \\ en la región de frontera del $R S$
}

Phillipp Dias Gripp

Doutor e mestre em Comunicação pela Universidade Federal de Santa Maria (UFSM)

e-mail: phidgripp@gmail.com

Joseline Pippi

Professora do curso de Comunicação Social da Universidade Federal do Sul da Bahia (UFSB) e-mail: josipippi@gmail.com

\section{Resumo}

Este artigo trata sobre os modos pelos quais as relações de poder interferem no discurso noticioso sobre ciência e tecnologia em jornais impressos de sete cidades da região fronteiriça do Rio Grande do Sul (RS). Para entendermos como isso ocorre, baseamo-nos na metodologia da Análise do Discurso objetivando analisar a forma como a temática científica é abordada em sete jornais da região de fronteira oeste e sul do RS, publicados durante o ano de 2010. Optamos por categorizar os enunciados em formatos jornalísticos e evidenciamos a existência dos formatos indicador, roteiro, cotação e notícia, além da necessidade de denominar três novos: o colunismo social científico, o relato de curiosidade e a informação prescritiva.

Palavras-chave: Jornalismo científico. Relações de poder. Fronteira.

\begin{abstract}
This paper addresses the ways in which power relations interfere in news discourse about science and technology (S\&T) in printed newspapers of seven cities in the border region of Rio Grande do Sul (RS/Brazil). To understand how this occurs, we are based on the Discourse Analysis methodology, aiming at analyzing the way in which the scientific theme is approached in seven newspapers in the region west and south of the RS, published during the year 2010. We chose to categorize the texts in journalistic formats and we evidenced the existence of the formats indicator, script, quotation and news, as well as the need to denominate three new: the scientific social column, the curiosity report and the prescriptive information.
\end{abstract}


Key words: Scientific journalism. Power relations. Border.

\section{Resumen}

Este artículo trata sobre los modos por los cuales las relaciones de poder interfieren en el discurso noticioso sobre ciencia y tecnología en periódicos impresos de siete ciudades de la región fronteriza de Rio Grande do Sul (RS/Brasil). Para entender cómo esto ocurre, nos basamos en la metodología del Análisis del Discurso para analizar la forma que la temática científica es abordada en siete diarios de la región de frontera oeste y sur de RS, publicados durante el año 2010. Optamos por categorizar los enunciados en formatos periodísticos y evidenciamos la existencia de los formatos indicador, guion, cotización y noticia, además de la necesidad de denominar tres nuevos: el columnism social científico, el relato de curiosidad y la información prescriptiva.

Palabras clave: Periodismo científico. Relaciones de poder. Frontera.

\section{INTRODUÇÃO}

Cientistas e jornalistas trabalham com instâncias distintas, mas ambos visam apresentar sentidos de verdade sobre fenômenos do mundo. Ao considerar especificidades de saberes, fazeres e procedimentos éticos, técnicos e estéticos das duas profissões, entende-se que suas práticas discursivas obedecem ao principal encargo de serem verossímeis. Neste trabalho, refletimos sobre o produto proveniente do vínculo entre esses dois domínios, as notícias científicas, importando-nos especialmente com a configuração da discursividade textual gerada a partir do aspecto relacional entre jornalistas (enunciadores) e cientistas (fontes), buscando apreender as possibilidades de sentido das informações disseminadas midiaticamente.

Oportuniza-se, então, uma investigação que objetiva evidenciar como as relações de poder se circunscrevem na produção noticiosa que retrata a temática da Ciência \& Tecnologia (C\&T), contribuindo para estruturação dos enunciados, por meio das relações instituídas entre os profissionais das redações jornalísticas e cientistas enquanto fontes de informação. Neste artigo, tal abordagem é delimitada ao corpus analítico de produção do jornalismo científico (JC) em mídias impressas na região de fronteira oeste e sul do RS.

Para tanto, partimos de uma distinção conceitual sobre as formas de propagação do conhecimento científico e enfocamos a discussão teórica na perspectiva das relações de poder como interferentes no âmago das produções jornalísticas sobre C\&T. Compreendemos que se evidencia a presença do fluxo conflituoso das relações de poder na produção do JC devido aos âmbitos científico e jornalístico se preocuparem de modos diferentes com as instâncias da educação e da verdade. Finalmente, adotamos metodologicamente a Análise de Discurso para 
identificar os contratos de comunicação aos quais os enunciados selecionados são condizentes, por meio da identificação de dados externos e internos (CHARAUDEAU, 2006). Considerando o enfoque jornalístico dos textos, optamos por categorizar os resultados em formatos que se enquadram em gêneros previamente definidos como informativo, opinativo, interpretativo, utilitário e diversional (COSTA, 2010). Dessa forma, a análise evidencia quatro formatos jornalísticos já existentes (indicador, roteiro, cotação e notícia) e se tornou necessário classificar três novos (relato de curiosidade, informação prescritiva e colunismo social científico).

\section{CIÊNCIA \& TECNOLOGIA (C\&T) EM PAUTA: CONCEITOS E DISTINÇÕES}

Por vezes, expressões como "comunicação científica", "disseminação científica", "divulgação científica" e "jornalismo científico" podem ser confundidas ou utilizadas como sinônimos, referindo-se a escritos jornalísticos sobre ciência. Logo, evidencia-se a necessidade de apresentar uma distinção conceitual entre as noções para demonstrar as especificidades de cada uma. Para tanto, apoiamo-nos em apontamentos conceituais de Bueno (1988), Epstein (2012) e Hernando (1977).

As considerações dos autores permitem vislumbrar uma aproximação teórica entre as noções de comunicação primária e comunicação secundária (EPSTEIN, 2012), e os níveis de difusão das informações para especialistas e para o público em geral (BUENO, 1988), respectivamente. A determinação das respectivas terminologias é baseada no destinatário da informação. Destina-se a comunicação primária e a difusão para especialistas aos sujeitos que já têm conhecimento prévio sobre o assunto científico abordado. A comunicação secundária e a difusão para o público em geral são destinadas a não-especialistas.

Nesse sentido, a comunicação científica ou disseminação científica são vistas como produções intrapares (produzidas de especialista para especialista), sem preocupações com uma abordagem linguística que possibilite o entendimento por não-especialistas. Por outro lado, a divulgação científica (DC) é um produto que transmite informações sobre C\&T numa linguagem inteligível e que possibilita a compreensão do assunto abordado também aos sujeitos não especializados. O JC, por sua vez, é uma produção sobre C\&T que prima pelas especificidades da prática jornalística. Para Marques de Melo (1985), o JC deve ser:

Uma atividade principalmente educativa. Deve ser dirigido à grande massa da nossa população e não apenas à sua elite. Deve promover a popularização do conhecimento que está sendo produzido nas nossas universidades e 
centros de pesquisa, de modo a contribuir para a superação dos muitos problemas que o povo enfrenta. Deve utilizar uma linguagem capaz de permitir o entendimento das informações pelo cidadão comum. Deve gerar o desejo do conhecimento permanente, despertando interesse pelos processos científicos e não pelos fatos isolados e seus personagens. Deve discutir a política científica, conscientizando a população que paga impostos para participar das decisões sobre a alocação de recursos que significam o estabelecimento de prioridades na produção do saber. Deve realizar um trabalho de iniciação dos jovens ao mundo do conhecimento e de educação continuada dos adultos (1985, p. 142).

Percebemos que fazer JC não se trata apenas de abordar a temática num produto jornalístico, devendo-se ainda obedecer a preceitos básicos. Neste sentido, Calvo Hernando (1977) evidencia a importância do JC para democratizar o conhecimento, elencando cinco objetivos fundamentais: 1) a compreensão da importância do apoio e estímulo pela C\&T; 2) possibilitar que a população usufrua de novos conhecimentos e técnicas científicas; 3) demonstrar a preocupação com o sistema educacional; 4) considerar o conhecimento e as novas tecnologias como bens culturais e estabelecer uma base de comunicação sobre a temática; 5) e servir como uma alternativa de comunicação entre os pesquisadores. Além disso, Calvo Hernando (1977) também atribui ao JC seis principais funções: 1) informativa; 2) educativa; 3) social; 4) cultural; 5) econômica; e 6) político-ideológica.

Sustentamos, então, o princípio de que todo produto de JC é, necessariamente, um trabalho de DC, considerando que ambos primam pela compreensão do assunto abordado por parte de destinatários não-especialistas. Ressaltamos, contudo, que a recíproca nem sempre é verificável: a DC pode ser realizada sem obedecer aos critérios do JC. A partir disso, importa agora entender os meandros relacionais dessas produções.

\section{A PRESENÇA DAS RELAÇÕES DE PODER NO NOTICIÁRIO SOBRE C\&T}

A produção do JC depende da relação entre jornalista e cientista, que por vezes é conflituosa. Consideramos que a relação entre esses sujeitos se estabelece numa perspectiva de "moeda de troca": enquanto o jornalista necessita das informações cedidas pelo pesquisador, este almeja a visibilidade proporcionada pela esfera midiática, da qual o jornalista se responsabiliza. Entretanto, há constrangimentos notórios durante a produção jornalística sobre C\&T, sendo as relações de poder uma variável inerente e balizadora ao discurso proveniente.

Pelo viés de Foucault (1979) o poder não se define numa validade de posse. Não é possível a um sujeito ter o poder, pois este se configura em conjunto às relações e nunca 
individualmente. Entende-se que não se poderia desempenhar o poder de forma isolada, logo, não se poderia deter um poder. As relações de poder são consideradas como um conjunto de ações que não têm como objetivo chegar a um fim, pois, ao cumprir com uma finalidade, encerraria as possibilidades de relações. Isso porque, "de modo geral, eu diria que o interdito, a recusa, a proibição, longe de serem as formas essenciais do poder, são apenas seus limites, as formas frustradas ou extremas. As relações de poder são, antes de tudo, produtivas" (FOUCAULT, 1979, p. 236).

As relações de poder se engendram ao sujeito por meio de valores e crenças, que definem suas escolhas e elucidam a ele aquilo pelo que se luta. Entretanto, não se deve atribuir às relações de poder uma propriedade negativa, já que são elas que concebem a sociedade numa base de troca entre indivíduos, seja ela democrática ou não. Entendemos e levantamos o debate de que as problemáticas relativas às relações de poder interferem diretamente na produção de JC por meio de duas principais instâncias: da educação e da verdade.

Partimos do princípio de que o material jornalístico-científico prima por ser um instrumento essencialmente informativo e que sua linguagem permite viabilizar um contexto que pode promover elucidações educativas junto ao público-leitor como apontam Marques de Melo (1985) e Calvo Hernando (1977). Por outro lado, os cientistas se relacionam com a educação institucionalmente através da contratação por universidades para docência e desenvolvimento de suas pesquisas, cujos resultados geram novos saberes e processos educativos. Concordamos que o domínio da educação, sob o prisma das relações de poder:

[...] embora seja, de direito, o instrumento graças ao qual todo indivíduo, em uma sociedade como a nossa, pode ter acesso a qualquer tipo de discurso, segue, em sua distribuição, no que permite e no que impede, as linhas que estão marcadas pela distância, pelas oposições e lutas sociais. Todo sistema de educação é uma maneira política de manter ou de modificar a apropriação dos discursos, com os saberes e os poderes que eles trazem consigo (FOUCAULT, 1996, p. 43-44).

Logo, educar também se caracteriza como uma variável das relações de poder, pois o enunciador do processo comunicativo constrói um discurso educativo a partir de suas escolhas e crenças, que causam e se originam através de permissões e impedimentos. Cada processo de educação depende de uma transmissão de saberes anterior ao discurso que se produz no presente. Ou seja, a produção de conhecimento e a própria DC dependem, antes da produção de um discurso que eduque, do conjunto de uma série de discursos anteriores que também 
educaram o atual enunciador. Entende-se que a DC, então, mascara-se como um sistema acumulativo de saberes que avançaram durante os anos, mas que ela também se direciona à perda de um conhecimento outro que, por vezes, não é dito, ora por escolha, ora por desconhecimento. Porém, crê-se que os não-ditos pela via do desconhecido foram determinados em algum momento pela escolha de outro enunciador.

Cientistas e jornalistas encontram-se, ainda, em perspectivas díspares, relacionadas à verdade, já que, segundo Foucault (1979), o poder é intrínseco à verdade e ela é produto do mundo em que se vive, idealizada e construída pelo humano, e é (re)produzida devido a diversas coerções, induzindo efeitos regulamentados pelo poder.

Há um combate "pela verdade" ou, ao menos, "em torno da verdade" entendendo-se, mais uma vez, que por verdade não quero dizer "o conjunto das coisas verdadeiras a descobrir ou a fazer aceitar", mas o "conjunto das regras segundo as quais se distingue o verdadeiro do falso e se atribui ao verdadeiro efeitos específicos do poder"; entendendo-se também que não se trata de um combate "em favor" da verdade, mas em torno do estatuto da verdade e do papel econômico-político que ela desempenha (FOUCAULT, 1979, p. 13).

No que se refere à produção noticiosa sobre ciência, por um lado, os cientistas detêm o status de verdade relacionado à pesquisa científica; enquanto que, por outro, é dever ético da profissão jornalística apresentar informações verdadeiras, sustentando, com isso, credibilidade no seu papel de mediação de informações. Atribui-se confiança ao discurso jornalístico, já que, por si só, a ética da profissão propõe a construção de enunciados que primam pela verdade. Enquanto isso, a verdade dos cientistas é percebida a propósito de um caráter historicamente estabelecido socialmente, que atribui a eles a qualidade de estarem em constante busca de sentidos verdadeiros sobre o mundo, a ponto de serem vistos como mitos, como aponta Alves (2013).

Apesar desse combate pelo discurso verídico, Foucault (1996) demonstra que as características do que é considerado como verdade mudaram historicamente. Para ele, o discurso verdadeiro, num primeiro momento era aquele realizado por quem teria direito atribuído de fazê-lo, e, mais tarde, por aquele que demonstra a veracidade ao obedecer a regras específicas para dizer o que diz. $\mathrm{O}$ valor de verdade teria deixado de estar sobre o sujeito que diz ou faz, passando para a forma que o enunciado é dito.

Logo, numa sociedade, quaisquer pessoas poderiam dizer uma verdade. Entretanto, apesar de ser "sempre possível dizer o verdadeiro no espaço de uma exterioridade selvagem; 
[...] não nos encontramos no verdadeiro senão obedecendo às regras de uma 'polícia' discursiva que devemos reativar em cada um de nossos discursos" (FOUCAULT, 1996, p. 35), compreendendo o conceito foulcaultiano de polícia como uma técnica e não como uma instituição do estado. Dessa forma, qualquer um pode dizer a verdade, desde que, para dizê-la, obedeça a determinadas regras para atribuir essa qualidade ao discurso.

Percebemos, assim, que existe uma notória luta "em torno da verdade" por aqueles que cumprem com distintas regras na elaboração de um discurso. Consideramos que as problemáticas relativas às relações de poder entre jornalistas e cientistas se dão por conflitos de verdade dentro de um sistema que gira em torno da educação, tomando ainda maior complexidade pela possibilidade de algum favorecimento a alguma das partes, seja pela informação que o cientista pode ceder ao jornalista, ou pela visibilidade que este pode proporcionar ao pesquisador.

\section{DELIMITAÇÕES DO CORPUS PARA ANÁLISE E APORTE METODOLÓGICO}

Os constrangimentos relacionais intensificam-se no contexto de empresas jornalísticas de interior, devido suas especificidades. Um dos maiores problemas nessas redações é a falta de qualificação acadêmica dos profissionais, já que, como Dornelles (2005, p. 39) evidenciou em sua pesquisa, "a qualidade do jornal é diretamente proporcional à presença de jornalistas formados". Os jornais de interior têm importância significativa para a população local, com a singularidade de retratar os acontecimentos da cidade onde são produzidos. Como constata Dornelles (2005), os leitores assinantes de jornais locais do interior do RS também acompanham outras publicações estaduais, não havendo necessidade de os jornais do interior competirem mercadologicamente com informativos estaduais e/ou nacionais.

Essa desnecessidade pode ser verificada a partir da análise de que a fronteira se torna notícia na grande mídia regional ou nacional, geralmente, quando o acontecimento está envolvido a estigmas, assinalados em quatro elementos recorrentes na mídia impressa, conforme apontou Silveira (2007):

Violência urbana e rural (assaltos, assassinatos, perseguição política a cidadãos de países vizinhos em território brasileiro); terrorismo (vínculos com grupos terroristas muçulmanos e colombianos); exclusão social (imigrantes e trabalhadores estrangeiros sem documentos e/ou direitos legais, clandestinidade, pobreza) e contravenções legais (contrabando de sementes transgênicas, alimentos, roupas e eletroeletrônicos, abigeato, tráfico sexual e de drogas) (2007, p. 11). 
Portanto, para se informar sobre os acontecimentos dos municípios onde vivem, os moradores da região de fronteira do RS dependem de uma empresa jornalística e das ponderações desta sobre quais fatos têm relevância a ponto de se tornarem notícia. Para se ter ideia da dimensão dessa região, convém perceber que a faixa de fronteira, determinada pela lei $n^{\circ}$ 6.634, de 02 de maio de 1979, regulamentada pelo Decreto ${ }^{\circ} 85.064$, de 26 de agosto de 1980, define um filete de $150 \mathrm{~km}$ de largura em território nacional. No RS 182 municípios integram a faixa, abrangendo $10 \%$ de todas as cidades de fronteira do país, sendo o estado com o maior número de municípios fronteiriços do Brasil, totalizando 39\% das cidades gaúchas, segundo a divisão territorial de 1999, registrada pelo IBGE, conforme mapa a seguir.

Mapa 1 - Delimitação da faixa de fronteira no RS, especificando as cidades dos jornais analisados

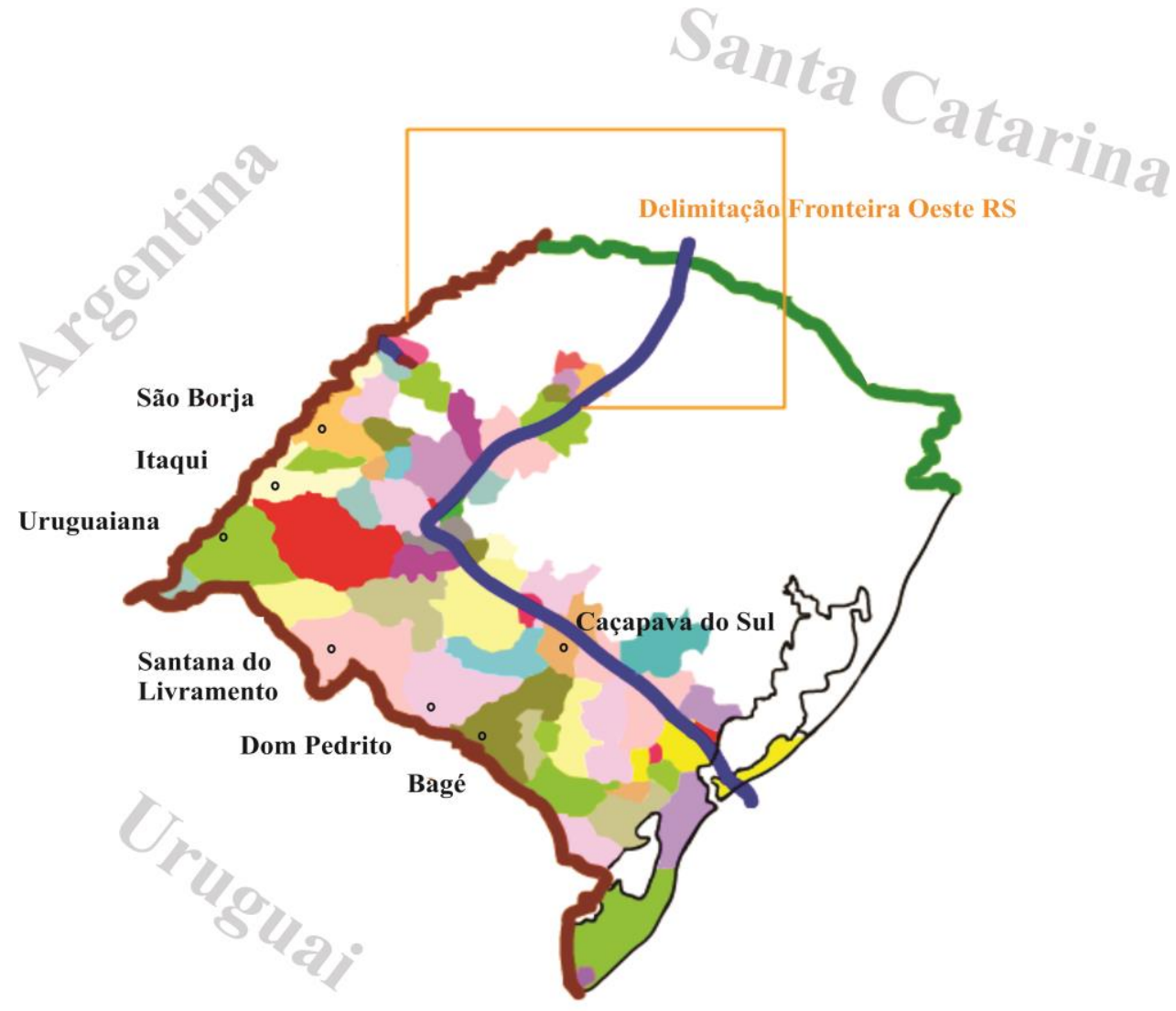

Fonte: Adaptado de IBGE (2014).

Com tal cenário em vista, este artigo enfocou na análise do discurso de 35 textos, veiculados durante o ano de 2010, que abordam a temática científica em sete jornais da região de fronteira oeste e sul do RS, apreendendo como as relações de poder, instituídas entre fonte de informação científica e jornalista, interferem nos formatos textuais. Os jornais elencados 
para análise são os mais antigos que ainda circulam em cada cidade. As características de cada periódico estão dispostas no quadro a seguir.

Tabela 1 - Especificidades dos periódicos analisados.

\begin{tabular}{|c|c|c|c|c|c|c|}
\hline Periódico & Cidade & Fundação & Periodicidade & $\begin{array}{c}\text { Dias de } \\
\text { Circulação }\end{array}$ & Tiragem & $\begin{array}{c}\text { Número } \\
\text { médio de } \\
\text { Páginas }\end{array}$ \\
\hline $\begin{array}{c}\text { Jornal } \\
\text { Cidade }\end{array}$ & Uruguaiana & $\begin{array}{c}01 \text { jun. } \\
1991\end{array}$ & Trissemanal & $\begin{array}{c}\text { Terças, } \\
\text { quintas e } \\
\text { sábados }\end{array}$ & 2800 & 16 páginas \\
\hline $\begin{array}{c}\text { Jornal } \\
\text { Minuano }\end{array}$ & Bagé & $\begin{array}{c}01 \mathrm{abr} . \\
1994\end{array}$ & Diário & $\begin{array}{c}\text { Todos os } \\
\text { dias }\end{array}$ & 4500 & 24 páginas \\
\hline A Plateia & $\begin{array}{c}\text { Santana do } \\
\text { Livramento }\end{array}$ & $\begin{array}{c}10 \text { jan. } \\
1937\end{array}$ & Diário & $\begin{array}{c}\text { Todos os } \\
\text { dias }\end{array}$ & 4000 & 24 páginas \\
\hline $\begin{array}{c}\text { Folha de } \\
\text { São Borja }\end{array}$ & São Borja & $\begin{array}{c}24 \text { fev. } \\
1970\end{array}$ & Bissemanal & $\begin{array}{c}\text { Quartas e } \\
\text { Sábados }\end{array}$ & 4000 & 32 páginas \\
\hline $\begin{array}{c}\text { Ponche } \\
\text { Verde }\end{array}$ & Dom & $\begin{array}{c}21 \mathrm{fev} . \\
1932\end{array}$ & Trissemanal & $\begin{array}{c}\text { Quarta e } \\
\text { Sábados }\end{array}$ & 2000 & 20 páginas \\
\hline $\begin{array}{c}\text { Nossa } \\
\text { Época }\end{array}$ & Itaqui & $\begin{array}{c}15 \mathrm{abr} . \\
1988\end{array}$ & Semanal & Sábados & 1500 & 12 páginas \\
\hline $\begin{array}{c}\text { Gazeta de } \\
\text { Caçapava }\end{array}$ & $\begin{array}{c}\text { Caçapava } \\
\text { do Sul }\end{array}$ & $\begin{array}{c}16 \mathrm{jul} . \\
1999\end{array}$ & Semanal & Sextas & 2000 & 16 páginas \\
\hline
\end{tabular}

Fonte: Elaboração própria.

Para a análise dos enunciados dos sete periódicos, embasamo-nos na proposta de contrato de comunicação de Charaudeau (2006), que é resultado das características de dados externos, que são não são essencialmente linguageiros, mas “constituídos pelas regularidades comportamentais dos indivíduos que aí efetuam trocas e pelas constantes que caracterizam essas trocas e que permanecem estáveis por um determinado período" (CHARAUDEAU, 2006, p. 68), e dos dados internos, que são discursivos e possibilitam entender como o discurso é dito.

Consideramos, então, as condições de identidade (quem diz e para quem), finalidade (para que se diz), propósito (o que se diz) e de dispositivo (em que condições se diz), ligados aos dados internos, e os espaços de locução (justificativa pela qual o enunciador se impôs como sujeito falante), relação (como as relações entre enunciador e destinatário estão estabelecidas e se apresentam no texto) e tematização (de que forma o assunto tratado no texto é organizado), atrelados aos dados externos. A identificação dos dados externos é necessária para posterior análise dos dados internos, pois estes estão diretamente associados ao discurso.

A partir da identificação das características discursivas dos dados externos e internos, a análise se debruçou em agrupar os textos com particularidades semelhantes para avaliar as 
marcas discursivas das matérias, com o objetivo de compreendê-las em grupos de formatos jornalísticos relativos a gêneros específicos. Compreende-se que a existência dos formatos encontrados se dá em decorrência da regularidade com que as marcas discursivas se apresentam nos textos analisados, já que “[...] é possível determinar formas textuais dominantes com o auxílio de certo número de traços que as constituam de maneira ideal, e que constituam modelos de escritura nos quais venham moldar-se os textos" (CHARAUDEAU, 2006, p. 234-235).

Optamos pela categorização em formatos jornalísticos, considerando a classificação de gêneros em informativo, opinativo, interpretativo, utilitário e diversional, conforme quadro 2 , a seguir, baseados em Marques de Melo e descrita por Costa (2010).

\begin{tabular}{|c|}
$\begin{array}{c}\text { Gênero Informativo } \\
\text { Primando pela objetividade, o gênero se atém à narração de relatos, intencionando pro- } \\
\text { porcionar ao leitor informações sobre o acontecimento para que ele adquira consciência } \\
\text { sobre o assunto. }\end{array}$ \\
$\begin{array}{c}\text { Gênero Opinativo } \\
\text { Intencionando uma opinião específica acerca de um acontecimento, o gênero se atém à } \\
\text { argumentação sobre o assunto tratado, objetivando expor os pensamentos do autor e } \\
\text { suas justificativas para tais percepções. }\end{array}$ \\
$\begin{array}{c}\text { Gênero Interpretativo } \\
\text { A partir de uma análise investigativa e pesquisa documental acerca do tema abordado, o } \\
\text { gênero prima pelo desenvolvimento de textos com profundidade que possibilite ao leitor } \\
\text { um entendimento amplo sobre o assunto. }\end{array}$ \\
$\begin{array}{c}\text { Gênero Utilitário } \\
\text { Centralizando na produção de conteúdos informativos baseados numa prestação de ser- } \\
\text { viço aos leitores, o gênero se estabelece numa finalidade textual que possa ser utilizada } \\
\text { em benefício do receptor. }\end{array}$ \\
Gênero Diversional \\
$\begin{array}{c}\text { Considerando as particularidades de estilo literário na elaboração de textos, o gênero } \\
\text { propõe a perspectiva de construções narrativas que contextualizem do leitor a respeito } \\
\text { de ambientações, características físicas de personagens, etc. }\end{array}$ \\
\hline
\end{tabular}

Quadro 1 - Classificação de gêneros jornalísticos a partir das considerações de Marques de Melo

Fonte: COSTA, 2010

Tal qual Costa (2010), nossa justificativa para categorizar os textos jornalísticos em gêneros e formatos é por sua legitimação nas redações e na academia, sendo "instrumentos pedagógicos válidos para o ensino e aprendizagem do fazer jornalístico [...] a expressão se justifica por indicar um texto cujo propósito comunicativo de maior peso seja o que o identifique, embora os outros possam aparecer de forma secundária” (2010, p. 43).

A nossa análise, então, busca evidenciar como os textos demonstram as relações de poder entre jornalista e cientista, percebendo a quais marcas discursivas são atribuídas maior visibilidade, resultando em abordagens textuais e formatos jornalísticos específicos. Cinco 
matérias de cada periódico foram selecionadas dentro de um universo de 468 textos, sendo a amostragem constituída aleatoriamente (não estatística). Destas 468 entradas 47 são do Jornal Minuano, 32 da Gazeta de Caçapava, 30 do Ponche Verde, 09 do Nossa Época, 84 do periódico A Plateia, 89 da Folha de São Borja e 177 do Jornal Cidade. Salienta-se que os títulos e trechos das matérias foram transcritos tal quais os originais, logo, eventuais erros foram mantidos. Os títulos das matérias analisadas, veiculadas durante o ano de 2010, assim como a indicação da data (dia e mês) estão dispostos no quadro 3 e atendem na análise pelo respectivo número antecedido pela letra "T" (Texto).

Tabela 2 - Relação dos 35 textos analisados.

\begin{tabular}{|c|c|c|c|}
\hline & Periódico & Data & Título \\
\hline T01 & Jornal Minuano & $12 / 01$ & Seios: aumentar ou diminuir? \\
\hline T02 & Jornal Minuano & $26 / 01$ & Instituto recruta voluntários para testar vacina contra gripe A \\
\hline T03 & Jornal Minuano & $02 / 02$ & $\begin{array}{l}\text { Que calor é esse? Meteorologistas preveem chuva acima da média } \\
\text { para fevereiro }\end{array}$ \\
\hline T04 & Jornal Minuano & $08 / 08$ & $\begin{array}{l}\text { Fibras solúveis no tratamento da doença hepática gordurosa não } \\
\text { alcoólica }\end{array}$ \\
\hline T05 & Jornal Minuano & $27 / 08$ & Embrapa apresenta tecnologias em Esteio \\
\hline T06 & Gazeta de Caçapava & $08 / 01$ & Projeto Alto Camaquã tem Dias de Campo \\
\hline T07 & Gazeta de Caçapava & $29 / 01$ & $\begin{array}{l}\text { Combate à febre amarela em Caçapava é tema de artigo em } \\
\text { revista nacional }\end{array}$ \\
\hline T08 & Gazeta de Caçapava & $05 / 03$ & Por que a Terra treme \\
\hline T09 & Gazeta de Caçapava & $04 / 06$ & Um novo conceito no tratamento da coluna: quiropraxia \\
\hline T10 & Gazeta de Caçapava & $12 / 11$ & O sono dos adolescentes \\
\hline T11 & Ponche Verde & $27 / 02$ & Retarde o envelhecimento comendo uma castanha por dia \\
\hline T12 & Ponche Verde & $17 / 07$ & Professor da Unipampa tem projeto aprovado pela Fapergs \\
\hline T13 & Ponche Verde & $27 / 08$ & Conjuntivite \\
\hline T14 & Ponche Verde & $11 / 09$ & Professor da Unipampa participa de missão científica na Rússia \\
\hline T15 & Ponche Verde & $15 / 09$ & Quem dorme menos engorda mais \\
\hline T16 & Nossa Época & $30 / 01$ & Clima sofrerá influência do El Niño até abril \\
\hline T17 & Nossa Época & $20 / 02$ & Aproveite o sol sem queimaduras \\
\hline T18 & Nossa Época & $27 / 02$ & Mantida a estratégia para combater o Aedes aegypti \\
\hline T19 & Nossa Época & $08 / 09$ & Arroz: movimentações cresceram $10 \%$ sobre julho \\
\hline T20 & Nossa Época & $25 / 09$ & Tempo seco \\
\hline $\mathbf{T 2 1}$ & A Plateia & $19 / 02$ & $\begin{array}{l}\text { Chuva e calor favorecem aparecimento de mofo branco na lavoura } \\
\text { de soja }\end{array}$ \\
\hline T22 & A Plateia & $23 / 05$ & Incêndio no Butantã espalha marcas também em Livramento \\
\hline $\mathbf{T 2 3}$ & A Plateia & $30 / 05$ & $\begin{array}{l}\text { O olhar debruçado do sociólogo sobre Sant'Ana do Livramento e } \\
\text { sua gente }\end{array}$ \\
\hline T24 & A Plateia & $12 / 07$ & Advogado de Livramento cursa Doutorado em Ciências Jurídicas \\
\hline $\mathbf{T 2 5}$ & A Plateia & $15 / 11$ & Um bicho que apavora muitas pessoas \\
\hline $\mathbf{T 2 6}$ & Folha de São Borja & $03 / 03$ & $\begin{array}{l}\text { Pesquisadores da Unipampa preparam viagem de volta da } \\
\text { Antártica }\end{array}$ \\
\hline T27 & Folha de São Borja & $10 / 03$ & Apitoxina - Veneno que cura ou mata? (I) \\
\hline $\mathbf{T 2 8}$ & Folha de São Borja & $16 / 10$ & Evolução da medicina \\
\hline T29 & Folha de São Borja & $30 / 10$ & $\begin{array}{l}\text { Acadêmica de Biologia da Urcamp selecionada para projeto } \\
\text { Tamar, em São Paulo }\end{array}$ \\
\hline T30 & Folha de São Borja & $29 / 12$ & $\begin{array}{l}\text { Urcamp analisa água do rio Uruguai usando o teste } \\
\text { 'Allium Cepa' }\end{array}$ \\
\hline T31 & Jornal Cidade & $26 / 06$ & Anvisa: pimentão lidera ranking do agrotóxico \\
\hline
\end{tabular}


PROGRAMA DE PÓS-GRADUAÇÃO EM COMUNICAÇÃO DA UNIVERSIDADE FEDERAL DE SANTA MARIA

\begin{tabular}{|l|l|l|l|}
\hline T32 & Jornal Cidade & $29 / 06$ & Amendoim pura proteína \\
\hline T33 & Jornal Cidade & $17 / 08$ & Primeiro feijão transgênico do mundo é brasileiro \\
\hline T34 & Jornal Cidade & $28 / 08$ & $\begin{array}{l}\text { Uruguaianense estuda a evolução da parasitologia e práticas } \\
\text { ecológicas }\end{array}$ \\
\hline T35 & Jornal Cidade & $09 / 12$ & Pesquisadora do Irga recebe Troféu Destaque Feminino Rural \\
\hline
\end{tabular}

Fonte: Elaboração própria.

A análise foi compreendida em cinco etapas: 1) categorização dos dados externos; 2) categorização dos dados internos; 3) agrupamento dos textos através da percepção de características de dados externos e internos semelhantes; 4) análise das marcas discursivas dos grupos organizados pela semelhança encontrada; e, finalmente, 5) categorização de gêneros e formatos jornalísticos.

\section{CATEGORIZAÇÃO DOS DADOS EXTERNOS E INTERNOS DO CONTRATO DE COMUNICAÇÃO}

A nossa análise evidenciou o seguinte agrupamento dos dados externos a partir das características dos periódicos, das autorias dos textos, da inteligibilidade dos enunciados e de uma compreensão geral da exposição de cada texto:

a) a condição de identidade se apresenta numa comunicação realizada de: Especialista para leitor interessado, quando o texto é assinado por um conhecedor da área científica e restrito a um público particular, pelo discurso ser dificilmente compreendido por não-especialistas; ou Especialista para leitor geral, quando o texto assinado pelo conhecedor da área pode ser compreendido por qualquer pessoa; ou Jornalista para leitor interessado, quando o texto não é assinado (entendendo-se que foi produzido pela equipe de redação) e é restrito a um público particular, pela difícil compreensão linguística; ou Jornalista para leitor geral, quando o texto não é assinado e pode ser compreendido por qualquer leitor.

b) a condição de finalidade foi percebida a partir das visadas propostas por Charaudeau (2006, p. 69), a saber:

A prescritiva, que consiste em querer "fazer fazer", isto é, querer levar o outro a agir de determinada maneira; a informativa, que consiste em querer "fazer saber", isto é, querer transmitir um saber a quem se presume não possuí-lo; a incitativa, que consiste em querer "fazer crer", isto é, querer levar o outro a pensar que o que está sendo dito é verdadeiro (ou possivelmente verdadeiro); a visada do páthos, que consiste em "fazer sentir", ou seja, provocar no outro um estado emocional agradável ou desagradável; 
c) a condição de propósito foi constituída como um resumo sobre o que, afinal, o texto expõe, no intuito e perceber o tema geral retratado em poucas palavras.

d) a condição de dispositivo se delimita ao suporte do corpus analisado, determinada pela especificidade da mídia impressa produzida e veiculada na fronteira do RS.

A partir da percepção das características dos dados externos, as matérias foram submetidas à análise de dados internos, para compreendermos o discurso e também organizálas em grupos com características semelhantes. Esta etapa de análise possibilitou agrupar os textos analisados nas seguintes possibilidades observadas em cada enunciado:

a) espaço de locução:

- visibilizar o acontecimento: a temática científica é atrelada ao acontecimento ou é utilizada para explicá-lo;

- visibilizar o indivíduo: a temática científica se apresenta no texto em decorrência da personagem;

- visibilizar o conhecimento: a temática científica é utilizada para possibilitar a propagação de um conhecimento específico;

b) espaço de relação:

- relação de desconhecimento (desconhecido): o discurso evidencia um valor de acontecimento que se refira à temática científica;

- relação de expectativa (aguardado): o discurso se refere a uma situação que já causou impacto no organismo social e necessita de uma explicação científica;

- relação de aplicabilidade (aplicável): o discurso se refere a uma informação ou conhecimento científico do qual o destinatário poderá se utilizar posteriormente;

- relação de curiosidade (curioso): o discurso não apresenta valor perceptível e se propõe a relatar um conhecimento que desperte curiosidade no leitor;

c) espaço de tematização:

- descritivo: o enunciado descreve um mundo estático;

- narrativo: aborda ações numa sequência de acontecimentos;

- $\quad$ argumentativo: apresenta raciocínios lógicos para comprovar um ponto de vista.

A partir da identificação dos dados externos e internos exposta, os 35 textos selecionados aleatoriamente foram, então, submetidos à análise discursiva e agrupados em diferentes formatos jornalísticos à medida em que apresentaram marcas semelhantes entre si. 
Na próxima seção, apresentamos as sete categorizações observadas e um resumo da análise, seguida de uma discussão analítica.

\section{ANÁLISE DAS MARCAS DISCURSIVAS E FORMATOS JORNALÍSTICOS}

A partir do agrupamento de textos com características iguais, esta seção foi dividida nos formatos categorizados durante a análise. Para exemplifica-los, foram transcritas partes dos textos que possibilitam demonstrar as características discursivas dos dados internos.

\subsection{Indicador (gênero utilitário)}

Dois textos foram categorizados no formato indicador (COSTA, 2010), que se baseia na publicação de dados importantes para que os indivíduos possam tomar decisões em seus respectivos cotidianos. Percebemos marcas discursivas deste formato expressas em textos que tratam sobre previsões meteorológicas a partir de informações científicas, como por exemplo: “A previsão para o mês de fevereiro, segundo os meteorologistas é de muito calor e chuvas constantes" (T03), “As previsões divulgadas dia 22, indicam maior probabilidade de chuvas abaixo da média" (T16).

\subsection{Roteiro (gênero utilitário)}

Dois textos foram categorizados no formato roteiro (COSTA, 2010), que se refere a informações indispensáveis para possibilitar ao leitor que usufrua determinado consumo. A análise encontrou a sua presença em textos relacionados a eventos de temática científica e de dias de campo, nos quais se dão ênfase aos locais de evento e programações, a exemplo de: “[...] Expointer 2010, que acontece de 28 de agosto a 5 de setembro, no Parque de Exposições Assis Brasil, em Esteio” (T05), “[...] farão outros sete dias de campo em Candiota, Pinheiro Machado, Piratini e Santana da Boa Vista. A atividade desenvolvida em Unidades Experimentais de Pesquisa Participativa, é voltada a pecuaristas familiares da região do Alto Camaquã" (T06).

\subsection{Cotação (gênero utilitário)}

Um texto foi categorizado no formato cotação (COSTA, 2010), que é relacionado a informações sobre a variação de dados específicos a diferentes mercados, como monetário, agrícola e terciário. Durante a análise ele se fez presente pelas mudanças em dados da área agropecuária. Por exemplo: "No primeiro semestre de 2009, as movimentações de arroz no 
Rio Grande do Sul atingiram 3,5 milhões de toneladas, mas deve-se considerar que em igual período, as exportações alcançaram um montante superior a 2010, em torno de 300 mil toneladas, o que justifica a redução das movimentações, em igual período, em 2010” (T19).

\subsection{Notícia (gênero informativo)}

Seis textos foram categorizados no formato notícia (COSTA, 2010), que se refere a um relato integral sobre um acontecimento que já eclodiu na sociedade, respondendo, necessariamente, às perguntas: que?; quem?; quando?; como?; onde?; e por que?. O formato foi encontrado principalmente quando relacionado a acontecimentos científicos ou quando um acontecimento necessitava de uma explicação científica, como por exemplo: "Começou esta semana o recrutamento de voluntários para testar a vacina que será produzida no País pelo instituto Butantã contra o vírus da Influenza A (H1N1)" (T02), "A Embrapa desenvolveu o primeiro feijão transgênico do mundo. A variedade, resultado de 20 anos de pesquisa, é resistente ao vírus do Mosaico Dourado, que destrói plantações em todo o país” (T33).

\subsection{Relato de curiosidade (gênero utilitário)}

A análise discursiva permitiu identificarmos cinco textos categorizados no formato nomeado "relato de curiosidade", que se caracteriza por uma informação com teor científico que supre uma curiosidade e/ou dúvida que se presume existir por parte do leitor. Não existe uma preocupação no discurso presente neste formato com os valores de notícia ou com relação a um acontecimento em particular, preocupando-se, apenas, em exaltar conhecimentos supostamente desconhecidos pelo destinatário. Foi possível percebê-lo em textos de caráter essencialmente utilitários, que partem de uma finalidade relacionada ao entretenimento, tornando-se um suporte para sanar possíveis dúvidas. Por exemplo: "Conforme o professor de Geofísica da Unipampa, Manuel Ivan Zevallos Abarca, o fenômeno acontece porque o contato entre as placas tectônicas e o deslocamento de suas camadas provoca uma forte pressão nas rochas" [T08], “As maiores aranhas podem chegar a $75 \mathrm{~mm}$ de comprimento, com envergadura de patas de cerca de $255 \mathrm{~mm}$. As fêmeas costumam ser maiores" [T25], "Foi após a dissecção de cadáveres que a anatomia humana foi estudada e deu oportunidades para a prática da cirurgia" [T28]. 


\subsection{Informação prescritiva (gênero utilitário)}

A análise discursiva permitiu identificarmos oito textos categorizados no formato nomeado "informação prescritiva", caracterizando-se pela associação à curiosidade do destinatário e enfatizando um indicativo sobre as possíveis causas de um ocorrido para, com isso, instituir os melhores procedimentos a serem tomados em benefício do indivíduo. A percepção do formato foi possível a partir de textos, principalmente, com recomendações relacionadas à área da saúde. Por exemplo: “A pessoa com conjuntivite tóxica deve se afastar do agente causador e lavar os olhos com água abundante" [T13], "O filtro solar deve ser

passado no corpo e no rosto 20 minutos antes da exposição ao sol [...]. É aconselhável o uso de chapéu e boné" [T17], "Saiba o que fazer para que a baixa umidade do ar não prejudique sua saúde" [T20].

\subsection{Colunismo Social Científico (gênero informativo)}

A análise discursiva permitiu identificarmos onze textos categorizados no formato nomeado "colunismo social científico", que foi assim denominado devido à ênfase atribuída de forma excessiva ao pesquisador, no objetivo de beneficiá-lo através de uma estratégia de visibilidade, utilizando-se de adjetivos que exaltam direta ou indiretamente a personagem científica. A incidência do formato partiu pela apreensão de que a figura do pesquisador se sobrepõe ao seu trabalho ou ao acontecimento científico, possibilitando discorrer sobre aspectos de sua vida pessoal, viagens ao exterior e aprovações, sem preocupação em discorrer sobre o trabalho realizado. A exemplo de: "O professor da Universidade Federal do Pampa (Unipampa), campus de Dom Pedrito, Paulo Rodinei Soares Lopes, teve um projeto de pesquisa aprovado no edital Auxílio Recém Doutor (ARD), da Fundação de Amaparo à Pesquisa do Rio Grande do Sul (Fapergs), com verba que totaliza R\$ 18.908,90” (T12), “Opinião firme, coerência, simplicidade, foco e objetivo. Sinônimos que são facilmente encontrados e aplicados em Fábio Régio Bento, professor adjunto da Universidade Federal do Pampa" (T23), "Com relevantes contribuições na área da parasitologia, em especial no quesito de ectoparasitas, Gonzales é uma referência nacional em medicina veterinária, devido aos seus estudos sobre carrapatos e seu controle nos rebanhos bovinos, com inúmeros trabalhos publicados, além de expressiva atuação na formação de recursos humanos" (T34). 


\section{DISCUSSÃO ANALÍTICA}

Quantitativamente, dos 35 textos analisados, 17 são do gênero informativo (seis notícias e onze colunismos sociais científicos) e 18 do gênero utilitário (dois indicativos, dois de roteiro, um cotação, cinco relatos de curiosidade e oito informações prescritivas). Num primeiro momento, a expressiva quantidade de textos do gênero utilitário possibilita evidenciarmos que a prática discursiva relacionada ao JC na região de fronteira do RS, circunscreve-se na constatação de textos que apresentam características muito mais relacionadas ao entretenimento, voltadas direta e/ou indiretamente à prestação de serviços à comunidade, do que aos objetivos de informar, explicar e analisar os acontecimentos a destinatários, de formas aprofundadas e com apuração adequada.

Ademais, os textos prescritivos, produzidos pelos pesquisadores, atêm-se à particularidade do formato pelo especialista que discorre sobre o assunto numa linguagem, por muitas vezes, ininteligíveis ao público não especialista. Esta opção linguageira utilizada culmina na confirmação da característica de quem tem propriedade para falar sobre o assunto, apesar da possibilidade de o leitor não conseguir compreender o discurso.

Enquanto isso, os relatos de curiosidade, por não demonstrarem um critério de noticiabilidade explícito durante as sequências discursivas e, tampouco, apresentarem uma comprovação de que o saber científico abordado textualmente seria, de fato, buscado pelo destinatário, possibilitam considerarmos que essa tipologia de discurso midiático apenas se estabelece partindo de um princípio de relação que confira visibilidade ao cientista.

As análises dos textos enquadrados como colunismo social científico permitem aferirmos que as informações sobre $\mathrm{C} \& \mathrm{~T}$ publicadas nos jornais impressos da região se constituem demonstrando as relações de poder existentes entre jornalistas e cientistas de forma clara, haja vista a visibilidade exacerbada atribuída aos pesquisadores através de adjetivos enaltecedores sobre eles próprios ou seus feitos.

As relações de poder se tornam perceptíveis através das análises discursivas pela apreensão de que as rotinas de apuração e redação, fundamentais para a formação da credibilidade do periódico, podem não ser seguidas à risca, o que é considerado pelo acontecimento científico muitas vezes não ser a matéria-prima da produção. Esses meandros de poder são percebidos como uma censura disfarçada de informação, levando em conta que: 1) a primazia jornalística relacionada à temática científica nos jornais analisados não é, por vezes, relacionada ao acontecimento, mas à própria detenção (enobrecendo a posse) do saber científico e ao próprio indivíduo; 2) a propriedade que o cientista tem para falar sobre o 
assunto em pauta por conta do lugar que ele ocupa na sociedade, em diversos momentos, sobressai-se à competência do jornalista como mediador da informação e da linguagem científica ao público não especialista.

Percebemos que as relações de poder interferem no discurso noticioso analisado. A produção jornalística sobre $\mathrm{C} \& \mathrm{~T}$ na região de fronteira do $\mathrm{RS}$ contribui para um distanciamento dos leitores em relação à temática científica, devido ao uso de termos técnicos de áreas do conhecimento distintas e à exaltação da personalidade e suas conquistas. Os textos optam por evidenciar os indivíduos ao invés dos acontecimentos e conhecimentos. Nestes jornais o indivíduo, além da possibilidade de construir notícia, é a própria notícia.

A análise evidencia, ainda, uma constante na produção jornalística sobre $C \& T$ na região: o estereótipo sobre a ciência estar ligada apenas a áreas duras do conhecimento é perceptível quando comparamos a quantidade de textos entre as áreas. Dentre os 35 textos analisados, 14 são da área de Ciências da Saúde, nove de Agrárias, seis de Biológicas, quatro de Exatas e da Terra e apenas uma de Sociais Aplicadas e uma de Humanas, enquanto as áreas de Engenharias e de Linguística, Letras e Artes não foram encontradas. O privilégio dado à veiculação de informações sobre as ciências duras contribui para uma mistificação da C\&T de que a produção científica se resume às áreas da saúde e natureza.

Vale salientar que a maioria dos textos analisados não se enquadram na perspectiva de JC apresentada neste trabalho e não contribuem efetivamente para a democratização do conhecimento científico, pois não cumprem aqueles objetivos e funções elencados por Calvo Hernando (1977). Desse modo, assinalamos que os textos analisados demonstram uma produção discursiva sobre C\&T em jornais impressos, mas não condizem aos preceitos do JC.

\section{CONSIDERAÇÕES FINAIS}

A categorização dos formatos de colunismo social científico (gênero informativo), relato de curiosidade e informação prescritiva (gênero utilitário), foi necessária tendo em vista os textos não apresentarem características discursivas evidentes que possibilitassem o enquadramento nos formatos jornalísticos considerados na obra de José Marques de Melo e organizados por Costa (2010), manifestando, ainda, particularidades expressivas que evidenciam a prática jornalístico-científica da região de fronteira do RS.

A categorização dos três formatos supracitados possibilita evidenciarmos aspectos das relações de poder entre jornalistas e cientistas na produção noticiosa sobre C\&T dos jornais da fronteira do RS, em que a visibilidade dada ao pesquisador é, por vezes, exacerbada, 
sobrepondo-se ao próprio acontecimento científico, podendo propiciar, em diversos casos, que o trabalho jornalístico seja visto como "desnecessário". Esta dispensabilidade, no entanto, acarreta em claras problemáticas na construção discursiva, impossibilitando, inclusive, que leitores não-especialistas possam entender o assunto abordado.

Enfim, compreendemos que os agentes da produção jornalístico-científica precisam entender as relações de poder que os cercam numa perspectiva que beneficia ambas as partes: aos jornalistas pelas informações credíveis cedidas para a elaboração de notícias e aos cientistas pela visibilidade possibilitada pelos veículos midiáticos. Faz-se necessário que as duas instâncias entendam e respeitem os modos de se "fazer saber" provenientes de seus respectivos costumes produtivos: que o cientista não prejulgue as construções enunciativas desenvolvidas pelos jornalistas, pois elas existem para que as informações sejam inteligíveis pelos leitores provavelmente não especialistas, tampouco que jornalistas se deslumbrem com cientistas, considerando-os como prepotentes e detentores de todo o saber. Apenas a partir desse contrato de mútuo benefício é que também será possível favorecer o destinatário da informação com uma produção jornalística capaz de democratizar o conhecimento.

\section{REFERÊNCIAS}

ALVES, R. Filosofia da ciência: introdução ao jogo e suas regras. São Paulo: Loyola, 2013.

BUENO, W. C. Jornalismo científico no Brasil: aspectos teóricos e práticos. ECA-USP: São Paulo, 1988.

CALVO HERNANDO, M. Periodismo científico. Madrid: Paraninfo, 1977.

CHARAUDEAU, P. Discurso das Mídias. São Paulo: Contexto, 2006.

COSTA, L. A. Gêneros jornalísticos. In: ASSIS, F.; MELO, J. M. (orgs). Gêneros jornalísticos no Brasil. São Bernardo do Campo: Universidade Metodista de São Paulo, 2010.

DORNELLES, B. Características de jornais e leitores interioranos no final do século XX. BOCC, Covilhã, v. 1, p. 1-15, 2005. Disponível em: <http://www.bocc.ubi.pt/pag/dornelles-beatrizcaracteristicas-jornais-leitores-interioranos.pdf>. Acesso em 08 abr. 2019.

EPSTEIN, I. Comunicação da ciência: rumo a uma teoria da divulgação científica. In: Organicom, São Paulo, ano 9, n. 16/17, p. 19-38, 2012.

FOUCAULT, M. A ordem do discurso. São Paulo: Loyola, 1996.

Microfísica do poder. Rio de Janeiro: Graal, 1979.

IBGE. Faixa de fronteira. 2018. Disponível em:

<http://www.ibge.gov.br/home/geociencias/geografia/fronteira.shtm?c=3>. Acesso em 08 abr. 2019. 
MELO, J. M. Jornalismo científico: a democratização do conhecimento. In: MELO, J. M. Para uma leitura crítica da comunicação. São Paulo: Paulinas, 1985, p. 139-145.

SILVEIRA, A. C. M. A identidade deteriorada: Jornalismo e estigmas sociais. Anais da XVI Compós, 2007. Disponível em: 〈http://www.compos.org.br/data/biblioteca_201.pdf〉. Acesso em 08 abr. 2019.

Original recebido em: 18 de abril de 2019

Aceito para publicação em: 28 de novembro de 2019

Phillipp Dias Gripp

Doutor pelo Programa de Pós-Graduação em Comunicação Midiática (linha de pesquisa Mídia e Identidades Contemporâneas) da Universidade Federal de Santa Maria. Mestre em Comunicação pela mesma instituição (2016). Bacharel em Comunicação Social com habilitação em Jornalismo pela Universidade Federal do Pampa (2014). Integrante do Grupo de Pesquisa Comunicação, identidades e fronteiras (UFSM). Dedica-se a investigações sobre lugares de fala, relações de poder, identidades, discurso e popularização científica.

\section{Joseline Pippi}

Professora da Universidade Federal do Sul da Bahia (UFSB), vinculada ao Instituto de Humanidades, Artes e Ciências Jorge Amado e ao Centro de Formação em Ciências Agroflorestais (Campus Jorge Amado, Itabuna). Foi professora do Curso de Jornalismo da Universidade Federal do Pampa (Unipampa 2007-2016), tendo participado da implantação do Curso e também do Campus São Borja/RS (2006). É Bacharel em Jornalismo (2004), Mestre (2005) e Doutora (2012) em Extensão Rural pela Universidade Federal de Santa Maria (UFSM). Desenvolve pesquisa com recorte territorial centrado na Região Sul da Bahia, especialmente nas seguintes temáticas: imprensa interiorana, jornalismo especializado e estratégias comunicacionais voltadas para a extensão rural.

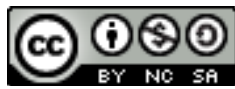

Esta obra está licenciada com uma Licença

Creative Commons Atribuição-NãoComercial-CompartilhaIgual 4.0 Internacional 